Šulcová J., Murgová A.

\title{
Quality of life in patients after acute coronary syndrome in a lifestyle context
}

\author{
Vysoká škola zdravotníctva a sociálnej práce sv. Alžbety, n.o. Bratislava, Slovakia
}

janulasulcova@gmail.com

\section{Introduction}

Our lives have always been associated with the heart's activity. Its rhythm, from the very beginning of life, expresses the age, joys, and worries. It often reflects good and bad or pleasant and unpleasant things in life. The heart is the first organ in the body that receives oxygenated blood and supplies the blood to the whole organism. The arteries nourishing the heart curl around its surface and form a kind of wreath. That is why they are called coronary arteries. Healthy (intact) coronary arteries can fully supply the heart muscle with blood even at maximum load. However, the information avoiding narrowing of the coronary arteries in the disease process has not been encoded by biological development in the human body. The most common diseases are atherosclerosis and thrombosis. Nowadays, the narrowing of the coronary artery is one of the most common heart diseases and it is considered an epidemic of the second half of the $20^{\text {th }}$ century. This range of manifestations is called ischaemic heart disease (IHD) and it mainly includes acute coronary syndrome (myocardial infarction and angina pectoris). The coronary arteries cannot be blamed since it is a disease that undoubtedly reflects our way of life. All diseases are characterised by various limitations, not only during the disease itself. Most treated diseases require a permanent lifestyle change. Acute coronary syndrome (ACS) belongs to this group as well. If a person overcomes it, it does not mean that his or her life will be the same as before. In order to prevent a recurrence of this disease, which is more likely to occur with each subsequent infarction, it is necessary to change some bad habits or common habits. Knowledge is a prerequisite for us to understand how to change our lives in order not to leave it prematurely because of our own guilt and lack of knowledge.

\section{Theoretical background}

Cardiovascular disease (CVD) causes approximately one-third of all deaths worldwide. ACS is a major cause of mortality and disability in patients. ACS is based on an acute form of ischaemic heart disease (IHD), which is caused in most cases by coronary atherosclerosis and concomitant thrombosis (1). Atherosclerosis is a systemic disease of the coronary arteries and is considered the leading cause of death and invalidity in the USA. It is estimated that there are 40 million people with ischaemic heart disease worldwide. In Slovakia, they account for $53 \%$ of total mortality and are one of the main causes of shorter life expectancy. IHD represents a wide range of pathologies and is divided into chronic IHD and acute coronary syndromes. Acute coronary syndromes represent a spectrum of ischaemic myocardial events and are divided into:

- non-ST-elevation myocardial infarction (NSTEMI);

- ST-elevation myocardial infarction (STEMI);

- sudden cardiac death (2).

All acute coronary syndromes, despite differences in their presentation, have a similar pathophysiological mechanism consisting of atherosclerotic plaque rupture, thrombus formation with the subsequent cessation of coronary flow of different degrees, and reduced oxygen supply to the myocardium. The more coronary arteries narrow, the more resistance is put up to the flowing fluid and so the lower current level is produced by the heart as a pump (3). In the past, atherosclerosis was considered the consequence of the excessive storage of cholesterol in the vascular wall. At present, atherosclerosis is understood as the consequence of the complex interaction of risk factors, with the inflammatory process playing a key role. ACS refers to an acute complication of the atherosclerotic process (2). The most common risk factors of CVD include controllable risk factors hyperlipidaemia, hypertension, smoking, obesity, stress, lack of physical activity, infections, diabetes mellitus and uncontrollable risk factors - age, men over the age of 45, women over the age of 55 and genetic factors (4). ACS is manifested by common symptoms in the chest - pain, pressure, tightness, and burning, which do not stop even if the person is at rest and lasts longer than 30 minutes. The coronary artery becomes blocked by a blood clot, and a part of the myocardium that has been nourished gradually dies. This process usually lasts for several hours and it might cause complete and irreversible damage to the heart muscle. Therefore, the patient should call for help if the symptoms go on for more than 5 minutes. ACS is a battle against time, every minute counts and is important for a further prognosis of the heart muscle. A priority aspect of treatment in patients with ACS is to open the blocked coronary artery and initiate efforts to minimize the extent of myocardial damage. For practical reasons, it is possible to set time intervals of ACS, namely the time of symptom onset, the time of the call for medical emergency and rescue services by the patient, the time of diagnosis of ACS by ECG and admission to a health care facility for reperfusion therapy through thrombolysis or primary percutaneous coronary intervention (PCI) (2). The interval from the onset of symptoms to reperfusion therapy is called the total ischaemic time.

"ECG - PCI" should be performed within 120 minutes, in patients with extensive anterior ACS it is necessary to apply stricter criteria "ECG - PCI" interval less than 90 minutes. The shorter the time, the better the prognosis of the patient suffering 
from ACS (2). Nowadays, early management of the Mobile Application STEMI is available to rescue teams but not to the public. The application enables audio and graphical notification of ECG delivery. It continuously updates information for the rescuer as well as the Cardio centre about the distance of the ambulance and the expected arrival. Early treatment is associated with the best results. Myocardial ischemia is often the leading cause of sudden death and, therefore, it is necessary to make the public aware of the typical clinical symptoms associated with ACS and call for help. To shorten the total ischaemic time, delay caused by the patient represents the main problem. Hiding the pain and symptoms of ACS and refusing to call for help can lead to unnecessary disaster. Patients have various reasons for delay in calling for help. They are reluctant to call for help, they believe that the difficulties are of temporary or extracardiac origin, or they are not familiar with them and so they decide to contact a general practitioner (5). An optimal approach should be characterised by the situation when people know the typical manifestations of ACS and call the emergency services as soon as possible.
The sooner revascularization is done, the greater the chance that the affected part of the heart muscle will recover. The scar will be smaller, and the heart function will be intact (6).

Urgent invasive diagnosis - coronarography examination luminography, can detect and quantify organic stenoses (7). Modern treatment focuses on the identification and revascularization of the most serious coronary stenoses responsible for the clinical manifestation of ACS - "culprit" stenosis. Nowadays, primary reperfusion therapy can be performed as mechanical arterial patency by percutaneous coronary intervention (primary PCI), or drug fibrinolysis can be applied. Treatment should include intensive preventive measures that can stabilize atheromatous plaques (atheromas) in general and reduce the risk of rupture, recurrence or even sudden death (2). Despite a significant decline in mortality in several European countries in the last decade, one in six men and one in seven women die from ACS. However, the significant reduction in CVD mortality cannot be attributed to a significant improvement in lifestyle, but pharmacological, invasive and surgical treatment options.

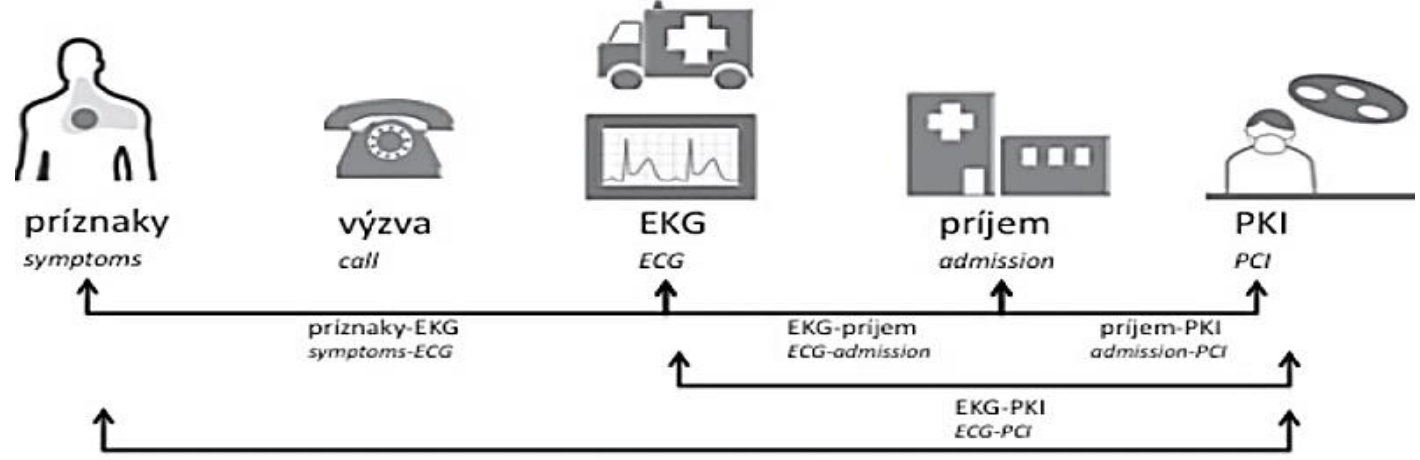

celkový ischemický čas

Picture. Total ischaemic time (Source: Studenčan, 2014)

A patient's quality of life after acute coronary syndrome. The consequences of cardiac muscle involvement depend on their size, the total ischaemic time and the initiation of reperfusion therapy. Moreover, they depend on the overall health of the patient and the age. Small vessel involvement and a part of the cardiac muscle at the optimal ischaemic time heal ad integrum, without consequences. A part of the cardiac muscle dies, but the rest of the muscle works normally. Shortly after a heart attack, the heart function is weaker. It takes one or even two months to recover fully. Massive heart attacks, late arrival for revascularization and treatment are serious problems. Moreover, massive heart attacks can lead to permanent impairment of myocardial performance. The dead part of the muscle heals itself by changing into a scar, but it cannot, however, replace the original tissue (8). The heart is then more sensitive to stress, and the function of pumping blood is often impaired. The blood stagnates in both circulatory systems and extra strain is put on the heart and lungs, what can lead to heart failure. The patient is recommended to go for regular check-ups at the cardiology clinic to be examined whether his health condition is getting better or worse and the response to treatment. All patients with acute coronary syndrome must take blood thinners and other medicines, depending on their health condition, to support the heart function as well as reduce high blood pressure and cholesterol.

Obesity and its effect on acute coronary syndrome. Overweight and obesity are major health problems nowadays. Hypertension, diabetes, and high cholesterol are closely related to obesity. These three factors are very dangerous because they negatively affect heart health. Obesity is among the leading causes of ischaemic heart disease, (IHD), myocardial infarction (5). Rising BMI increases the CVD risk, starting at a BMI of $21 \mathrm{~kg} / \mathrm{m}^{2}$. Weight exerts a higher demand on the heart of an obese person in comparison with a person of normal weight. It is, therefore, necessary to treat obesity as soon as possible. Non-pharmacological measures include mainly weight control. Weight loss of as little as $5 \mathrm{~kg}$ can reduce blood pressure by approximately $4 \mathrm{~mm} / \mathrm{Hg}$.

Elevated cholesterol is the cause of atherosclerosis, ACS. Small LDL particles are extremely dangerous since they deposit on the vessel wall and contribute to the formation of atherosclerotic plaques. LDL cholesterol is "bad" cholesterol and its level should be as low as possible. HDL cholesterol is 
"good" cholesterol because excess cholesterol is transported by its particles to the liver, where it is further processed. Its level should be as high as possible. Controlling levels of fat in the blood is an integral part of appropriate care for a patient after ACS.

Table 1. Body mass index $\left(\mathbf{k g} / \mathbf{m}^{\mathbf{2}}\right)$ (Source: Rodionov, 2016)

\begin{tabular}{l|l|}
\hline Normal weight & BMI $18.5-24.9$ \\
\hline Overweight & BMI $25-29.9$ \\
\hline $1^{\text {st }}$ degree obesity & BMI $30-34.9$ \\
\hline $2^{\text {nd }}$ degree obesity & BMI $35-39.9$ \\
\hline $3^{\text {rd }}$ degree obesity & BMI $>4$
\end{tabular}

Table 2. Recommended levels of fat in the blood in patients after ACS (Source: Špinar, 2007)

\begin{tabular}{l|l} 
Total cholesterol & $<4.5 \mathrm{mmol} / 1$ \\
\hline LDL cholesterol & $<2.5 \mathrm{mmol} / 1$ \\
\hline HDL cholesterol & $>1.0 \mathrm{mmol} / 1$ \\
& u mužov a $>1.2 \mathrm{mmol} / 1$ \\
\hline Triacylglycerols & $<1.7 \mathrm{mmol} / 1$
\end{tabular}

Diabetes mellitus is another health problem that affects people with obesity, especially if BMI is over 30 . The average life expectancy of patients with diabetes is reduced by a quarter (4). Diabetes mellitus and obesity are closely related; more than $80 \%$ of patients with diabetes are overweight, half of them suffer from obesity. It means a 7 to 28 times greater risk of developing diabetes. Central obesity is associated with higher risk factors because fat accumulates mainly in the abdominal area. In addition to the BMI values, it is necessary to know the waist circumference. It should not exceed $102 \mathrm{~cm}$ for men and $88 \mathrm{~cm}$ for women.

Lifestyle changes in connection with diet changes. When reducing weight, it is important to eat properly, it is not enough to cook tasty. Food is our daily companion, and improper eating habits can lead to many diseases. Weight loss also reduces the risk of coronary heart disease, diabetes mellitus, and hypertension. To lose weight, it is not recommended to be on a diet, but to change eating habits individually. Everyone should do the following:

1. Healthy eating is associated with fresh food. Consume cooked food immediately and do not store food in the fridge or heat it after a few days

2. It is important to eat everything that grows on trees or under the ground. Honey, eggs, herbal decoction, dried and fresh fruit with added honey and green tea should be incorporated into a diet plan.

3. Excess fat in food:

a) retains radioactive elements,

b) requires a large loss of energy for digestion from the body itself. It can cause deformation of the digestive tract (liver, stomach or duodenum),

c) deep-frying food can produce carcinogens,

d) excess fat clogs blood vessels what leads to heart attacks and strokes (a blood vessel looks like a frying pan covered with a layer of frying oil, and a lot of force is needed to clean it). Fat-containing products can be consumed by people who spend most of their time in the fresh air and do hard physical work (9).

4. Only eat when you are hungry. Feelings of hunger can be often mistaken for appetite signals. When you feel hungry, you should drink water with honey, lemon juice or tea and hunger will disappear. This way the feeling of hunger is "tested". The hunger will appear after a while only when the stomach is empty. If the stomach is starving, it slowly returns to its capacity of about $350 \mathrm{~cm}^{3}$.

5 . The food should be healthy, tasty, and simple.

6. Excess fat also results in a pathetic look of a person, because the muscles are overgrown with folds. If a person is obese and lazy, it can lead to heart diseases.

7. The popular high-fat cuisine has contributed to the poor state of health of the society for the last 30 years, so it is necessary to change eating habits as soon as possible.

8 . Those who find it difficult to say goodbye to a large amount of food can eat whatever they want, but folds on their abdomen should not exceed 1-2 cm (9).

Eating habits can be changed easily. Eating in moderation does not kill the person, one dies of overeating.

\section{Gradual transition to a healthier diet.}

Stage 1

The transition to a different diet should be gradual. We start with vegetable juices (one glass twice a day) and do not change the current diet (for 1-1.5 months). We gradually add more salads and vegetables to the menu so that $30-40 \%$ of the daily diet would consist of raw food, cooked or stewed vegetables. The ratio between raw and cooked food should be $60 \%$ of raw food and $40 \%$ of cooked food. When planning the daily menu, a simple rule should be followed: we eat what grows on the ground, underground, on trees, eggs, honey, sour dairy products. We also drink herbal teas, eat a lot of vegetables, fruits, and drink juices (8)

Stage 2

- The order of food consumed: drink fluids 20 minutes before meals and eat fruits before meals.

- If it is possible, try to avoid food bad for your health: (black tea, coffee, smoked meat products, desserts, sweets or fried foods).

- Let your body get into a raw food diet gradually: consume $50 \%$ of raw vegetables, $50 \%$ of cooked or roasted vegetables, drink a glass of freshly prepared vegetable juices daily.

- Each dish should contain stewed or raw vegetables.

- Consume fruits according to the season during the day: only apples, grapes, melons or strawberries. In summer and autumn, eat nothing but strawberries or melons or cherries the whole day.

- For breakfast, eat fruits and vegetables and drink fruit and vegetable juices; for dinner, eat salads, cottage cheese, fish, eggs, and before going to bed, drink a glass of kefir.

- If possible, exclude semi-finished and canned products from the menu.

- Salt restriction - salt causes water retention in the body, so people with cardiac problems should avoid salted 
foods. Reduced table salt intake leads to a considerable reduction of slightly elevated blood pressure. People, who add salt to a dish as soon as they sit down at the table, are likely to have typical hypertensive behaviour. In case this way of eating is not stopped, it will lead to hypertension (9).

- Cut down on sugar - sugar negatively affects the heart function. It can damage and block blood vessels, develop hypertension, and cause recurrence of heart attacks as fats. Triglycerides are to blame. People who eat more sugar than it is recommended per day, are more likely to have a twice higher risk of recurrent heart attacks. People who have suffered a MI should be very careful about sugar intake because their blood vessels are mostly damaged, and excessive sugar intake could make this condition worse (4). Too much sugar in food, sweetened drinks, and sweets should be avoided. A can of a sugary drink contains 30 to 40 grams of sugar (5 teaspoons of sugar).

- Drinking regime - fluid intake should be small amounts frequently. A person is made up mostly of water and the whole life is dependent on the constant intake of fluids. Fluids dilute the blood and thus prevent the risk for blood clotting; if a drinking water regimen is not followed, there is a risk of a recurrent heart attack (9).

When losing weight, physical activity is very important. The calories we consume must be burned, and so the movement is crucial after suffering any cardiovascular disease.

Physical activity after acute coronary syndrome. Medical and rehabilitation care is recommended for all patients after ACS. There they are monitored by various professionals, including physiotherapists. Sport, exercise, and physical activity can enhance health. They prevent the development of obesity as well as hypertension and reduce the amount of fat in obese patients. For patients after ACS, dynamic exercise is recommended, where the rhythmic contraction of muscle groups alternates with their release. Such exercises include walking, running, swimming, horseback riding, or crosscountry skiing and they do not require holding the breath too much. Strength exercises, where the individual muscles contract against resistance when holding the breath, are not suitable (10). These include strengthening exercises, bodybuilding, carrying, and lifting heavy objects or construction work. Team sports, such as volleyball, tennis, and football are appropriate diversification of endurance training.

The best form of physical exercise, after being released from the hospital, is a walk. The distance can be gradually extended, running short is allowed. Cycling can be the next activity. It is important to warm up before each exercise because excessive overloading of stiff muscles can lead to a variety of muscle and joint injuries. Exercise should be performed regularly, at least 3 times a week, depending on the patient's general health. It is recommended to drive a motor vehicle on the $7^{\text {th }}$ day after discharge from the hospital, in complicated patients (after cardiopulmonary resuscitation, hypotension or severe arrhythmias) it is recommended to postpone the driving for 2-3 weeks. Flighting by plane in the first two weeks is suitable only for stabilized patients, without dyspnoea, psychological alteration due to excessive fear of air transport. Plane cabins have an air pressure that is equivalent to the outside air pressure at 2,200-2,400 m, so reduced oxygen pressure can cause hypoxia in patients. Patients after ACS are often concerned about the quality of their life, which is also associated with sexual ability and performance. Fear of sexual failure and complications create anxiety and tension, leading to a loss of self-confidence and depression. Sexual activity as a natural part of life has a relaxing effect and poses very little risk in terms of mental and physical strain. It can be restored after 7-10 days. ACS should be an adequate reason for changing the way of life, which also includes relaxation. The path to material pleasures and career is paved with the risks that can be compared to the coronary artery with an atherosclerotic plaque.

Smoking and its effect on acute coronary syndrome. Smoking is a significant influential risk factor that contributes to several cardiovascular diseases. The most common diseases are ischaemic heart disease and strokes. Smoking affects the onset and course of atherosclerosis. Nicotine activates the sympathetic nervous system, acts on the vascular system and causes an increase in systolic blood pressure and heart rate. After smoking one cigarette, the blood pressure rises by up to $20 \mathrm{mmHg}$ and remains elevated for another 30 minutes. Smoking damages the endothelium and causes a higher adherence of platelets, which life span is decreasing. At the same time, the process of blood clotting is accelerating, and the blood viscosity is increasing as well.

Carbon monoxide enters the blood from the cigarette smoke. There it reduces the amount of oxygen carried to the heart and other body organs. Cigarette smoking significantly increases the risk of CVD. It also increases cardiovascular risk and the risk of death when combined with hypertension. Smoking cessation should be an essential part of treating hypertension. IHD is characterized by a disorder of heart function caused by myocardial hypoxia due to changes in the coronary arteries. Smoking increases the consumption of oxygen by the myocardium and influences the narrowing of the coronary arteries, which can worsen the symptoms of coronary heart disease. Increased levels of carboxyhaemoglobin cause a lack of oxygen in the blood, heart rate is increased by nicotine, and thus the consumption of oxygen in the heart muscle myocardium is increased. Smokers with angina pectoris develop chest pain faster during exercises than non-smokers with the same disability (12). Smoking also increases the risk of developing IHD, which is two to three times higher in smokers, with the relative risk of dying from a myocardial infarction being the highest in young smokers. Quitting smoking means a reduction in the risk of developing IHD by up to $50 \%$ in one year, in advanced disease a reduction in mortality by up to $30 \%$. When quitting smoking, it is necessary to motivate patients, to warn them about the possible problems and to advise them to set a quit smoking date. In most cases, patients need help in quitting smoking, so not only further professional consultation is needed, but also motivation from the patients themselves.

Stress and acute coronary syndrome. Both acute and chronic stress contributes to the pathogenesis of atherosclerosis and IHD, so the influence of psychosocial factors is a prevention challenge. Stress factors act at various degrees and are very 
diverse. Adrenaline is released during the body's stress response causing high blood pressure, heart rate, blood sugar, and fats (13). In the past, the organism used to prepare for the "fight-orflight" stress response. Nowadays, if a person does not have the opportunity to burn the energy released by stress, then stress has an adverse effect, especially on CVD. Diseases related to ACS are associated with stress. The patient is excluded from normal life suddenly, temporarily but sometimes permanently, and must change his life and work plans. He is often in social isolation and he feels useless. And so, the patient's family is very important in the process of quitting smoking. The members of the family should not only support a healthy diet or weight reduction, but they should also provide psychosocial support to overcome social isolation. Stressful circumstances can often be prevented or alleviated by appropriate hobbies, exercises, relaxation, yoga practice, sleep, and mental hygiene.

\section{Conclusions}

Acute coronary syndrome belongs to the diseases that are the result of a combination of several risk factors, which can be uncontrollable or controllable. Everyone takes charge of the factors which can be affected by preventive activities. Most of the risk factors are associated with the so-called modern lifestyle; therefore, ACS is classified as a disease of civilization. Health should be the number one priority for the individual, family, and society. It is also a prerequisite for an active life. Moreover, it affects our daily activities, which we perform either at work as duties or in our personal lives. It is influenced by many factors, such as lifestyle, health, and preventive behaviour of the patient, quality of life, or interpersonal relationships. In health care, health promotion and disease prevention have become important elements, which include efforts to improve overall health. The most important factors in health care are not the financial resources, technical and material equipment of health services, but individuals themselves; their way of thinking, living and willingness to participate effectively in their health care, to show will and perseverance, be intolerant to own laziness, arm themselves with knowledge and seek the way to health because as the old Eastern saying says: "Who does nothing, does not satisfy his own needs".

\section{References}

1. O’Rourke, R., Walsh, R., Fuster, V. 2010. Kardiologie. Hurstův manuál pro praxi. Praha: Grada Publishing, a. s., 2010, 800 p. ISBN 978-80-247-3175-9.

2. Studenčan, M. 2014. Akútny koronárny syndróm. Bratislava: Media Group, s. r. o., 2014, 240 p. ISBN 978-80969790-1-1.

3. Jacobs, A. K., Antman, E. M., Ellrodt, G., Faxon, D. P., Gregory, T., Mensah, G. A., et al. 2006. Recommendation to develop strategies to increase the number of ST-segment-elevation myocardial infarction patients with timely acces to primary percutaneous coronary intervetion. Circulation 2006; 113(17):2152-63.

4. Sovová, E., Sedlářová, J. 2014. Kardiológia pro odbor ošetřovatelství. 2. vyd. Praha: Grada Publishing, a. s., 2014, 255 p. ISBN 978-80-247-4823-8.

5. Fuhrman, J. 2018. Skoncujte s nemocemi srdce. Brno: CPress, 2018, 376 p. ISBN 978-80-264-2060-6.

6. Kamenský, G. 2011. Aktuálne trendy v starostlivosti o pacientov so STEMI na Slovensku. Analýza výsledkov registra Slovaks-2 z roku 2011. Cardiology Letters 2013; 22(2):115-124. (b).

7. Mitro, P., Valočík, G. 2009. Vyšetrovacie metódy v kardiológii. Košice: EQUILIBRIA, s. r. o., 2009,340 p. ISBN 978-80-89284-26-9.

8. Danchin, N., Cuzin, E. 2006. Srdečný infarkt, jak mu předcházet a jak se s ním vyrovnat’. Praha: Portál, s. r. o., 2006, 119 p. ISBN 80-7667-077-1.

9. Tombek, M. 2016. Kniha zdravého života. Český Těšín: Beskydy, 2016, 280 p. ISBN 987-80-87431-40-5.

10. Rodionov, A. 2016. Zdravé srdce. Ako predíst' infarktu a mŕtvici. Banská Bystrica: TBB, a. s., 2016,160 p. ISBN 978-80-8111-323-9.

11. Špinar, J., Vítovec, J. 2007. Jak dobře žít s nemocným srdcem. Praha: Grada Publishing, a. s., 2007,256 p. ISBN 978-80-247-1822-4.

12. Tóthová, E., Chloubová, I., Prokešová, R. 2019. Význam ošetřovatelství v preventívni kardiologii. Praha: Grada Publishing, a. s., 2019, 160 p. ISBN 978-80-271-2412-13.

13. Šimon, J. 2001. Epidemiológie a prevence ischemické choroby srdeční. Praha: Grada Publishing, spol. s r. o., 2001, 264 p. ISBN 80-247-0085-9.

Дата надходження рукопису до редакції: 03.06.2020 p.

Конфлікт інтересів: відсутній.

Conflicts of interest: authors have no conflicts of interest to declare.

\section{Автор для листування}

PhDr. Šulcová Jana - doctoral student VŠZaSP sv. Alžbety v Bratislave. janulasulcova@ gmail.com. 


\title{
Consequences of chronic wounds on patient's life
}

\author{
St. Elizabeth University of Health and Social Sciences, Field office in Michalovce, Slovakia
}

vierkai@centrum.sk,mriab9@gmail.com

\section{Introduction}

Chronic wounds are a health problem that has a negative impact on patients' lives and contributes to the increased costs of the healthcare system. They are often perceived as a disease of the elderly, because its peak incidence is between the ages of 60 and 80 , but it is clear that the onset of one's disease can date back to productive age.

A chronic wound is any disruption of the physiological continuity of body tissue, regardless of its size, associated with trauma or clinical conditions with a complex healing process that lasts for more than six weeks [1]. Despite progress in care and treatment, they usually have their own hidden pathological stimulus (diabetes mellitus, vascular insufficiency, etc.), which produces a recurring and prolonged stroke, leading to severe damage. A chronic wound does not heal in the normal healing stages, it often remains in the inflammatory, infected stage and causes discomfort and suffering to the patient.

If we consider the consequences of chronic wounds on patients' lives, we cannot forget to mention social discomfort, mobility problems, unpleasant odour, etc. Chronic wounds can cause significant physical disability, chronic pain, which can lead to permanent disability of the patient, to the need for assisted housing, depression, social isolation, or even to death.

Modern medicine and nursing call for the need for comprehensive treatment and patient care and for an individual approach to the treatment of chronic wounds. It is necessary to perceive the patient as a holistic being and to comprehensively evaluate all factors influencing the wound healing process [2].

Aim - to draw attention to the consequences of chronic wounds, which affect the daily life of a patient with a chronic wound.

Chronic wound. A wound is defined as a disruption of the continuity of the skin surface and the integrity of the organism, a disruption of the anatomical structure and function of the skin, caused by various elements reaching more or less deep into the subcutaneous tissues [3].

Chronic wounds occur in trophically altered tissue or in secondary dehiscence, and they do not tend to heal for 9 weeks. The time factor varies in several authors, some state 6 weeks while others up to 12 weeks [4]. The Czech Society for Wound Treatment defines a chronic wound as "a secondary healing wound which, despite adequate therapy does not show a tendency to heal in 6-9 weeks [5].

The most common types of chronic wounds are:

- lower leg ulcers of the venous etiology are one of the manifestations of chronic venous insufficiency;
- arterial skin ulcers are a manifestation of advanced ischemic disease of the lower limbs;

- ulcerations arising from diabetes mellitus (Wagner classification grade 1-5);

- pressure ulcers (stage I-IV);

- exulcerating malignancies;

- vasculitis - ulcerating types;

- secondary ulceration in systemic diseases;

- extensive burns;

- per secundam healing defects - surgical, traumatic;

- post-radiation wound;

- skin ulcers in the field of lymphedema;

- unrecognized infections - bacterial, fungal, viral, sexually transmitted diseases;

- parasitic diseases;

- self-harm;

- $\quad$ reduced pain threshold;

- other causes (obesity) [4,6].

Pospíšilová [3] states that regardless of the type and extent of the wound, the wound healing process takes place in 3 stages, which overlap independently. These are: an inflammatory or exudative phase in which bleeding is stopped and wound cleaned, proliferative (granulation) phase with the formation of new granulation tissue and vascular proliferation, and reepithelialization phase with epithelial differentiation and scar formation. Failures in the healing process include the following complications: stagnation of the cleansing phase, deceleration of the granulation phase, lack of epithelialization, formation of hypertrophic scars, postoperative complications (seromas, hematomas, wound dehiscence), microbial, fungal and viral infections.

Risk factors can affect wound healing. Some of the risk factors are immutable, but can be managed with nursing care, medication, and diet [1]. Immutable risk factors include age and impaired mobility. Potentially manageable chronic risk factors are: poor cardiovascular function, vascular disease, intestinal incontinence. Risk factors that can be influenced include: diet, unplanned weight loss, poor glycemic control, smoking and poor hygiene. In general, individuals with multiple risk factors have a higher risk of developing a chronic wound. The way chronic wound is being treated and healed, prolongs the healing process [7].

Incidence of chronic wounds. We consider chronic wounds to be a public health problem. They affect $5 \%$ of the adult population in Western countries, with chronic wounds occurring in $1-2 \%$ of the population in Central Europe, with $4-5 \%$ of patients with such wounds being people over 80 [8]. 
The incidence of chronic wounds is currently on the rise. A preliminary search of the literature suggests that in the Slovak Republic there is currently no relevant source for determining the overall incidence and prevalence of chronic wounds, and neither are there any consolidated data available on a European scale.

We partially relied on data from the EWMA (European Wound Management Association), according to which the incidence of chronic wounds across Europe is 3,581,927 / year [9]. The most common chronic wound of the lower limb is an ulcer disease caused by chronic venous insufficiency. In general, the presence of venous lower limb ulcers is reported in approximately $1-2 \%$ of the population over 65 years of age. The peak of prevalence of this disease is after the age of 60 . These wounds are more common in women. The second large group of patients with non-healing lower limb wounds are patients diagnosed with diabetes mellitus. The third important group are patients with bedsores (pressure ulcers) [10].

In 2017, according to the National Center for Health Information (NCZI), we registered 354726 diabetics in the Slovak Republic, which represents 6517 cases per 100,000 inhabitants [11]. According to NCZI statistics, in 2017 in Slovakia 8596 cases of diabetic foot with lesion were reported and 4196 amputations of the lower limbs were performed [12].

Diabetic foot syndrome is defined as an infection, ulceration or destruction of deep tissues, associated with neurological abnormalities and varying degrees of foot ischemia. The International Register of Lower Limb Amputation Procedures (VASCUNET) points to large differences between countries. Slovakia is a country with the highest number of low amputations: in front of Germany, Hungary and Australia, while in the number of high amputations we are just behind Hungary, in front of Austria, Finland and Germany. While the number of amputations abroad is declining, we are witnessing an opposite trend here. In the Slovak Republic, there was also the highest number of diabetics in amputations (74.3\%) [13].

After any operation, in 5-20\% cases, a healing failure of the surgical wound can occur and in $2-5 \%$ of those cases these can be more serious infections. A complication of a surgical wound can destroy the result of an otherwise perfectly performed procedure. On the other hand, there is a number of patients who cannot be operated because of their chronic wounds [14].

Negative aspects of chronic wounds. Negative aspects of chronic wounds are reviewed in terms of quality of life and in terms of economic costs. Reliable socio-economic data in this area are limited. In addition, chronic lower limb wounds are not sufficiently underpinned by health care. Patients often hide them, not only by clothing, but also intentionally from doctors because they do not trust them, are afraid of social stigma, feel anxious, embarrassed or are afraid of the costs associated with treatment. Chronic wounds present high costs for health care services because they require home care, long-term hospitalizations, comprehensive treatments and adjuvant treatments, and are associated with a high recurrence rate. In this context, people with chronic wounds experience changes in body image, mobility disorders, lack of self-care, inability to perform daily activities, pain and discomfort, which negativelly effects the quality of one's life [15].

To evaluate the effects of the disease and its treatment on human life validated tools and scales are used. They serve as an indicator of the response to treatment in people with chronic wounds, taking into account physical, psychological and social aspects, functional status and vision of life. Studies of this type make it possible to identify clinical factors that affect quality of life and compare the results with scientific evidence that favors the development of nursing interventions and policies to improve care for people with chronic wounds [16].

As a result of improved healthcare, patients have been living with disability-causing chronic wounds for many years. For these people, the quality of life can be as important as the quantity of life. Health-related measures dealing with quality of life seek to assess patients' mental and social health, not just their physical problems. Wound care is an ideal area for evaluating quality of life, as these problems are rarely life-threatening, but can have a major impact on patients' lifestyle. Eventhough preliminary studies have been performed to develop tools specifically for lower limb ulceration and chronic venous insufficiency, they have not addressed similar issues in other types of wounds. Evidence suggests that chronic wounds have a significant impact on patients' health, especially in relation to body pain, mobility, and psychiatric comorbidity [17].

There are many other health problems (comorbidities) in patients with venous leg ulcers. For example, $20 \%$ of patients suffer from depression, $30 \%$ from hypertension, $25 \%$ from osteoarthritis and $10 \%$ from diabetes. Ultimately, a significant number of patients with venous leg ulcers have a reduced quality of life due to mobility impairment, depression, feelings of social isolation, fear, anger, anxiety, negative self-perception, from reduced time spent at work up to the loss of work with an adverse impact on patient's financial situation [18].

Physical consequences of chronic wounds. Pain is the most commonly reported symptom of chronic lower limb wounds and is mentioned in each of the found studies, regardless of the research design. It is also present in venous ulcers and often worsens in wound dressing or when improperly managed [19].

In venous ulceration of the lower limb, pain has the greatest impact on reducing quality of life, with up to $12-21 \%$ of patients reporting severe pain. Similar results were obtained by the study, which suggested that for up to $38 \%$ of respondents, disease-related pain is the most significant limitation in social life [20].

According to Green and Jester [21], up to $81 \%$ of patients in their study reported reduced mobility. Chronic wounds present a significant threat to various dimensions of patients' quality of life. The main reason for restricted mobility is, above all, the pain that results from a chronic wound. Such limited mobility is often complicated by the leakage of exudate from the dressing material and the associated odour of the wound. Finding appropriate and comfortable clothing and footwear that can hide bandages is also a common problem. In an Australian study of women with chronic wounds, the respondents describe how they had to change their clothes in 
order to hide their wounds. This study also describes other lifestyle limitations that lead to an erosion of their femininity [22]. Several studies in patients with chronic lower limbs wounds have shown varying degrees of reduction in vitality. Chase et al [23] states a large energy deficit in patients suffering from chronic lower limb wounds. Sleep disorders are very common in those patients. These sleep disorders are mainly caused by the pain of the wound. Such insomnia results in daily fatigue as well as in lack of strength and energy.

Social and societal consequences of chronic wounds. In his study, Hopkins [24] states that chronic lower limb wounds, especially due to exudate and odour, have a significant impact on patients' social lives. Patients reported that they had difficulty controlling these disturbing symptoms and feared reactions from their immediate surroundings. The result of these fears and embarrassment was voluntary social exclusion and resignation from social contacts. Social isolation is a significant accompanying feature of chronic wounds [18]. They lead to disability and disability impairs wound healing, thus creating a vicious circle. Disability and wage loss associated with chronic wounds represent a major socioeconomic burden for patients with chronic wounds [10].

Our practical experience and information from interviews with patients with chronic wounds confirm that chronic wounds seriously impair their social status. Patients tell the nurse about their anxiety of the disease complications and subsequent disability. There is a disruption of work and other personally important relationships, which in turn decreases their zest for life. For many patients, missing or unsuitable prosthetic devices also present a problem, as they do not know where and how to ask for them, how often and to what prosthetic device they are entitled, in many cases they do not know how to use them correctly.

Economic consequences of chronic wounds. Approximately $20 \%$ of Slovak patients in working age are treated for chronic wounds of the lower limbs. Out of the total estimated number of 45692 people affected by chronic lower limb wounds, approximately 9138 are of working age up to 65 years of age. It is estimated that in Slovakia approximately 914 people in working age are unable to work due to a chronic lower limb wound [25].

Thus, a chronic wound can not only limit the patient's freedom, but also their income. Douglas [19] draws attention to the experience of many patients who, prior to the disease outbreak, used to be a head of the family with responsibility for its other members, but became dependent on them afterwards. Financial uncertainty is the worst issue for them, especially for men, the breadwinners having dependent children. The negative aspect is the fear of the future and dependence on supportive people. They often feel they are being a burden to their partner or children.

Lack of financial resources for the treatment is also a serious issue, as the treatment of a chronic lower limb wound is rather expensive and the dressing material, as well as many drugs and wound coverings needs to be paid extra.
Psychological consequences of chronic wound. Many patients suffer from an unhealthy obsession with their wound, which is a constant part of their thoughts. Some patients deliberately attempt to "normalize a wound" in an effort to live a normal life [24].

In patients with chronic wounds, we observe a disruption of their partnerships and family relationships, which also has a negative impact on the intimate and sexual life of patients with chronic wounds [26].

According to the results of clinical studies, deterioration of mental health is very common in patients with chronic wounds, the incidence of depression and anxiety is increased [18].

The European Wound Management Association (EWMA) found a significant link between a patient's mental well-being and basic physiological processes in wound healing [27].

\section{Conclusions}

Looking at the various studies from a psychosomatic point of view, it is clear that patients with chronic wounds suffer from significantly restricted activity and mobility, severe pain and increased concerns about their health and disability. In general, there is a serious deterioration in the physical, social, psychological and financial areas. In addition, these patients show significantly lower self-esteem. Poor mental state worsens wound healing which can result in a vicious circle with serious negative health consequences for the patient.

As part of a nursing practice, the nurses are in close contact with chronic wound patients. In this regard, it is important that they have sufficient skills and knowledge in the field of chronic wound healing [2], that they are erudite not only medically but also socially, so they can provide the patients and their families with true and appropriate advice in this area.

In the case of chronic wounds, depending on the indication, supportive communication, psychotherapy and psychopharmacological treatment should be considered. Effective communication with the patient can reveal several problems in the area of the their psychosomatic problems, and it is always good if the patient can find in their nurse a psychological help and a support for solving their problems. Neither must we forget to satisfy the inner - spiritual needs of the patient. https://www.karger.com/Article/Abstract/70529.

Chronic wounds are a significant and often underestimated burden on the individual, the healthcare system and society as a whole. Information on the prevalence of chronic wounds and their consequences on life is important for policy and planning purposes, as the increasing number of older people and the incidence of diseases of civilization indicate an increased burden [28]. Knowledge of the occurrence of chronic wounds and their consequences on everyday life in relation to population characteristics is important for health, social care planning and resource allocation. 


\section{References}

1. Salomé, G.,M, et al. 2016. Influence of venous leg ulcers on body image and self-confidence. Adv Skin Care Wound Care. 2016; 29 (7): 316-21.

2. Popovičová, M. 2020. Novyje napravlenija po zaživleniju ran. Ukrajina. Zdorovja naciji, 3030,3 (60): 120-124. ISSN 2077-6594.

3. Pospíšilová, A. 2013. Quality programs and standards of treatment procedures. Healing of chronic wounds. Online. Cited 8. november 2013, Available online: www.cslr.cz/download/hojeni-ran-standard.pdf.

4. Hlinková, E., Nemcová, J., Hul'o, E. et al. 2019. Management of chronic wounds. Grada Publishing, a.s., 2019. Prague. 20 p. ISBN 978-80-271-2687-3.

5. Stryja, J.2008. Summary of wound healing. 1. ed. Semily: Geum s.r.o., 2008. 199 p. ISBN 9788086256603.

6. Zelenková, H. 2020. Amputations in diabetic foot syndrome - quo vadis? In: Belovičová, M., Makara, P.: Proceedings of scientific works: Days of practical obesitology and metabolic syndrome 16.-18.07.2020. Collegium Humanum, Wasaw Management University. 350 p. ISBN 978-83-958245-0-0.

7. Litchford, M.2019. Proactive approach to the prevention and treatment of chronic wounds. 2020. [online]. Available online : https://www.asaging.org/blog/proactive-approaches-help-prevent-and-treat-chronic-wounds-0.

8. Sen, C.,K, Gordillo, G.,M., Roy, S., et al. 2009. Human Skin Wounds. A Major and Snowballing Threat to Public Health and the Economy. Wound repair and regeneration : official publication of the Wound Healing Society [and] the European Tissue Repair Society. 2009;17(6):7.

9. Bowler, P., G., Duerden, B., I., Armstrong, D., G. 2001.Wound microbiology and associated approaches to wound management. Clin Microbiol Rev 14, 244-269.

10. Margolis, D. J.2012. Epidemiology of Wounds. In: Mani R. et al. (eds.), Measurements in Wound Healing, Springer-Verlag London 2012.

11. Fábryová, L', Holéczy, P. et al.: Diabezita. Diabetes and obesity - inseparable twins. Brno: Facta Medica, 2019: 336 p. ISBN 978-80-88056-09-6.

12. NCZI. 2018. Activities of diabetological clinics in the Slovak Republic. Bratislava 2018. [online]. Available online: http://data.nczisk.sk/statisticke_vystupy/Diabetologia/Cinnost_diabetologickych_ambulancii_v_SR_2017.pdf.

13. Gašpar, L', Ambrózy, E., Mesárošová, D., Ludék, V., 2020. Amputations in diabetic foot syndrome - quo vadis? In: Belovičová, M., Makara, P.: Proceedings of scientific works: Days of practical obesitology and metabolic syndrome 16-18.07.2020. Collegium Humanum, Wasaw Management University. 350 p. ISBN 978-83-958245-0-0.

14. Mani, R., Romaneli, M., Shukla, V.,2013. Measurements in Wound Healing, Science and Practice, Springer, 2013 , ISBN 978-1-4471-2987-5.

15. Newbern, S. 2018. Identification of pain and effects on quality of life from chronic wounds to secondary vascular disease with lower extremity: An integrated review. Adv Skin Care Wound Care. 2018; 31 (3): 102-8.

16. Cavassan, N.,R.,V. et al. 2018. Correlation between chronic venous ulcer exudate proteins and clinical profile: A cross-sectional study. J Proteomics. 2018; 192: 280-90.

17. Franks, P.,J., Moffatt, CH.,J. 2013. Quality of life issues in the treatment of chronic wounds. British Journal of Community Nursing VOL. 4, NO. 6 Published online: September 27, 2013. [online]. Available online : https://doi.org/ 10.12968/bjen.1999.4.6.7476.

18. Ebbeskog, B., Ekman, S. 2001. Elderly people's experiences: the meaning of living with venous leg ulcer. European Wound Management Association Journal. 2001, 1 (1): 21-23 Franks, et al: Community leg ulcers. Phlebology 83-86, 1994.

19. Douglas. V. 2001. Living with a chronic leg ulcer: an insight into patients' experiences and feelings. Journal of Wound Care, 2001, 10(9): 355-60.

20. Hareendran, A.et al.2005. The impact of venous leg ulcers on quality of life. Journal of Wound Care, 2005, 14(2): $53-7$.

21. Green, J., Jester, R. 2010. Health-related quality of life and chronic venous leg ulceration: part 2. Wound Care, March 2010.

22. Rich, A., McLachlan, L. 2003. How living with a leg ulcer affects people's daily life: a nurse-led study. Journal of Wound Care. 2003, 12(2): 51-54.

23. Chase, S. et al. 2000. Living with chronic venous leg ulcers: a descriptive study of knowledge and functional status. Journal of Community Health Nursing, 2000, 17(1): 1-13.

24. Hopkins, A. 2004. Disrupted lives: investigating coping strategies for nonhealing leg ulcers. British Journal of Nursing. 2004, 13(9): 556-63.

25. Mokán, M. et al. 2008. Prevalence of diabetes mellitus and metabolic syndrome in Slovakia. Diabetes Res Clin Pract. 2008 Aug;81(2):238-42.

26. Posnett, J., Franks, P., J. 2008. The burden of chronic wounds in the UK. Nursing Times, 2008, 104:3, 44-45. [online]. Available online: https://www.nursingtimes.net/clinical-archive/tissue-viability/the-burden-of-chronic-wounds-in-theuk-23-01-2008. 
27. Palfreyman, S. 2008. : Assessing the impact of venous ulceration on quality of life. Nursing Times, 2008, 104(41): 34-37.

28. Järbrink, K. et al.2016. Prevalence and incidence of chronic wounds and advertising Related complications: protocol for systematic review 2016; 5 (1): 152. Published online September 8, 2016 doi: 10,1886/s13643-016-0329-y. PMCID: PMC5017042.

Дата надходження рукопису до редакції: 05.08.2020 p.

Конфлікт інтересів: відсутній.

Conflicts of interest: authors have no conflicts of interest to declare.

\section{Відомості про авторів}

PhDr. Viera Ivanková - St. Elizabeth University of Health and Social Sciences, student of doctoral study, Michalovce, Slovak Republic.

vierkai@centrum.sk.

assoc. Prof. Mária Belovičová, MD. PhD - St. Elizabeth University of Health and Social Sciences, Bratislava, Field office in Michalovce, Slovak Republic.

mriab9@gmail.com. 